We thank Dr T Jones (Oxfordshire Health Authority), Dr M Stern (Coventry Health Authority), Dr P Berrey (Lothian Health Board), Dr R Elton (University of Edinburgh), Dr M Pierce (Imperial College School of Medicine), and Dr S Campbell (National Primary Care Research and Development Centre) for regular discussions about the planning and implementation of this project, the doctors and practices who participated, and their managers and reception staff.

Contributors: JGRH, DJH, and MM initiated the study and wrote the protocol, along with GKF, and led the design of the analyses, which were carried out by JJW. All authors contributed to the design of research instruments, to the recruitment and briefing of practices, and to the interpretation of the results. JGRH, DJH, MM, and JJW wrote the paper, which GF helped to edit and develop.JGRH will act as guarantor for the paper.

Funding: The work was supported by grants from the chief scientist's office at the Scottish Office Home and Health Department and the research and development directorates of Anglia and Oxford NHS, West Midlands NHS, and North Thames NHS.

Competing interests: None declared.

Secretary of State for Health. A first class service-quality in the new NHS. The new NHS. London: Stationery Office, 1998.

2 Secretary of State for Health. A national framework for assessing performance. The new NHS. London: Stationery Office, 1998.

3 Donaldson LJ, Muir Gray JA. Clinical governance: a quality duty for health organisations. Oual Health Care 1998;7:37-44S.

4 Campbell SM, Roland MO, Quayle JA, Buetow SA, Shekelle PG. Quality indicators for general practice: which ones can general practitioners' and health authority managers agree are important and how useful are they. J Public Health Med 1999;20:414-21.

5 McColl A, Roderick P, Gabbay J, Smith H, Moore M. Performance indicators for primary care groups: an evidence based approach. $B M J$ 1998;317:1354-60.

6 Majeed F, Voss S. Performance indicators for general practice. BMJ 1995:311:209-10.

7 Baker R, Streatfield J. What types of general practice do patients prefer? Exploration of practice characteristics influencing satisfaction. Br J Gen Pract 1995;45:654-9.

8 Campbell JL. The reported availability of general practitioners and the influence of practice list size. Br J Gen Pract 1996;46:465-8.
9 Campbell SM, Roland MO, Shekelle PG, Cantrill JA, Buetow SA, Cragg DK. The development of review criteria for assessing the quality of management of stable angina, adult asthma and non insulin-dependent diabetes mellitus in general practice. Qual Health Care 1999;8:6-15.

10 Feder G, Griffiths C, Highton C, Eldridge S, Spence M, Southgate L. Do clinical guidelines with practice based education improve care of asthmatic and diabetic patients? A randomised controlled trial in general practices in east London. BMJ 1995;311:1473-8.

11 Little P, Smith L, Cantrell T, Chapman J, Langridge J, Pickering R. General practitioners' management of acute back pain: survey of reported practice compared with clinical guidelines. BMJ 1996;312:485-8.

12 Deane M, Crick D. Outcome of low back pain in general practice. Evidence based practice can improve outcome. BMJ 1998;317:1083.

13 Langham S, Gillam S, Thorogood M. The carrot, the stick and the general practitioner: how have changes in financial incentives affected health promotion activity in general practice? Br J Gen Pract 1995;45:665-8.

14 Buck D, Godfrey C, Morgan A. The contribution of health promotion to meeting health targets: questions of measurement, attribution and responsibility Health Promotion Int 1997:12:239-50.

15 Howie JGR, Porter AMD, Heaney DJ, Hopton JL. Long to short consultation ratio: a proxy measure of quality of care for general practice. $\mathrm{BrJ} \mathrm{Gen}$ Pract 1991;41:48-54.

16 Howie JGR, Hopton JL, Heaney DJ, Porter AMD. Attitudes to medical care, the organization of work, and stress among general practitioners. $B r$ J Gen Pract 1992;42:181-5.

17 Howie JGR, Heaney DJ, Maxwell M. Measuring quality in general practice. London: Royal College of General Practitioners, 1997. (Occasional paper 75.)

18 Pereira Gray D. Forty-seven minutes a year for the patient [editorial]. $\mathrm{Br}$ ] Gen Pract 1998;48:1816-7.

19 Howie JGR, Heaney DJ, Maxwell M, Walker JJ. A comparison of a patient enablement instrument (PEI) against two established satisfaction scales as an outcome measure of primary care consultations. Fam Pract 1998;15:165-71

20 Hjortdahl P. General practice and continuity of care: organisational aspects. Fam Pract 1989;6:292-8.

21 Hjortdahl P, Laerum E. Continuity of care in general practice: effect on patient satisfaction. BMJ 1992;304:1287-90.

22 Freeman G, Hjortdahl P. What future for continuity of care in general practice? BMJ 1997;314:1870-3

23 Lazarus RS. Patterns of adjustment. New York: McGraw-Hill, 1976.

24 Cockburn J, Killer D, Campbell E, Swanson-Fisher RW. Measuring general practitioners' attitudes towards medical care. Fam Prac 1987;4:192-9.

(Accepted 29 July 1999)

\title{
Rapid appraisal of needs in reproductive health care in southern Sudan: qualitative study
}

\author{
Celia A Palmer
}

\author{
Abstract \\ Objectives To identify the need for reproductive \\ health care among a community affected by conflict, \\ and to ascertain the priority given by the community \\ to reproductive health issues. \\ Design Rapid appraisal. This comprised interviews \\ with key informants, in-depth interviews, and group \\ discussions. Secondary data were collated. Freelisting, \\ ranking, and scenarios were used to obtain \\ information. \\ Setting Communities affected by conflict in southern \\ Sudan. \\ Participants Interviews and group discussions were \\ chosen purposively. Twenty interviews with key \\ informants were undertaken, in-depth interviews were \\ held with 14 women, and 23 group discussions were \\ held. \\ Main outcome measures Need for reproductive \\ health care. Perceived priority afforded to \\ reproductive health issues in comparison with other \\ health problems.
}

Results Reproductive health in general and sexually transmitted diseases in particular were important issues for these communities. Problems in reproductive health were ranked differently depending on the age and sex of the respondents. Perceptions about reproductive health issues in communities varied between service providers, and community leaders. Settled and displaced communities had different priorities and differing experiences of reproductive health problems and their treatment.

Conclusion Rapid appraisal could be used as the first step to involving communities in assessing needs and planning service provision

\section{Introduction}

Until the late 1980s little attention was paid to the opinions of communities receiving relief aid. Accountability of non-governmental workers, where it existed, was to the organisation with which they worked and to donor agencies. The humanitarian world has become 
increasingly concerned that the provision of aid has, on occasion, had negative consequences for the intended beneficiaries. ${ }^{1-3}$ Observations of aid provision reveal serious concerns, such as a lack of account paid to the context of particular situations and a failure to appreciate or use the capacities of the recipient communities. ${ }^{4-6}$ Steps are now being taken to improve accountability to beneficiaries. ${ }^{7}$

In addition to these developments there has been a move towards the introduction of reproductive health services in the context of conflicts. The international conference on population and development held in 1994 heralded a shift away from population control towards a more holistic view of women's health. ${ }^{8}$ At the conference the particular problems for populations affected by conflict were recognised. The document referred to "migrants and displaced persons [who] in many parts of the world have limited access to reproductive healthcare and may face specific serious threats to their reproductive health and rights." ${ }^{8}$ The United Nations and other agencies began discussions on what services should be provided. ${ }^{9}$ However, little but anecdotal evidence was available on the reproductive health status of populations affected by conflict. ${ }^{10}$ In addition there had been almost no systematic gathering of information on how beneficiaries prioritised reproductive health or on the services they wanted, nor was there a recognised method for gathering such information. This study, commissioned by Oxfam, had two aims: to identify the need for reproductive health care among a community affected by conflict in southern Sudan and to ascertain the priority given by the community to reproductive health issues in this context.

Sudan is the largest country in Africa, with an estimated population of around 25 million. A civil war has been continuing largely between the peoples of the north and those of the south. Since 1983 an estimated 1.2 million people have been killed, and the number of internally displaced people has been estimated at 4 million. The area where the study took place was in the hands of rebels and under constant threat from aerial bombardments. In this region some people were living in their own homes-"settled"-but some had been uprooted-"displaced."

\section{Methods}

\section{Selection of methods}

In emergencies needs are most often assessed using rapid assessment procedures. ${ }^{11-13}$ These do not routinely include contributions from the community. This contrasts with the techniques of rapid appraisal, ${ }^{14-16}$ which have been used in many different contexts, including in the United Kingdom, to assess health needs in primary care. ${ }^{17}$ The original objectives were to provide good quality and timely information, and to include local people, producing results that would lead directly to interventions.

For this study several methods of rapid appraisal were selected in order to deliver results in a short time frame, to address sensitive topics, and to be flexible enough to be used in a conflict zone. These methods were: interviews with key informants, in-depth interviews with women, group discussions, and the collation of secondary data. Semistructured question- naires were drawn up to use as a guide ${ }^{18}$ for interviews with key informants and for in-depth interviews. A topic guide was used for group discussions; it included general questions about wellbeing and specific questions about reproductive health. The questionnaires and topic guide were drawn up in advance and were based on previous qualitative work on reproductive health. ${ }^{19-22}$ They were piloted and revised in the field.

\section{Interviews with key informants}

Three types of key informants were selected: $(a)$ administrators, leaders, and other authorities; (b) community based outreach workers; and $(c)$ members of the study population. This range of key informants has been recommended for use in qualitative research. ${ }^{22}$

\section{In-depth interviews}

These interviews were undertaken solely with women as they were most likely to face problems in reproductive health and their views were the most difficult to access. The advantages of in-depth interviews are that respondents can often speak more freely and the interviewer is able to probe in depth about topics without interruption. The disadvantages include the possibility that the answers are lacking in spontaneity. In-depth interviews took place at the same villages where group discussions were held. The women were sampled by spinning a pen on the ground at a central point in the village. The researcher walked in the direction in which the pen pointed. Women living in consecutive houses in this direction were interviewed.

\section{Group discussions}

Group discussions were chosen to generate ideas and provide information about social views and attitudes. Random sampling of villages was attempted but abandoned as some villages were considered inaccessible because of their location or insecurity. Villages were instead chosen to give a spread across both urban and rural populations and to include both settled and displaced people. Village leaders were informed of the study the day before when possible, and volunteers were then assembled on the day the discussions took place.

\section{Ranking, freelisting, and scenarios}

Several techniques were used in the discussions and interviews. The first of these was freelisting, whereby respondents are asked to develop lists of illnesses, healthcare resources, or community priorities. ${ }^{23}$ Their main advantage is that they give an idea of the degree of general awareness of a problem. ${ }^{22}$ Freelisting was used in all interviews and group discussions. The second technique was matrix ranking, whereby problems or illnesses are ranked according to several different criteria. ${ }^{24}$ This provides information about the priority the community gives to one problem over another. Common diseases identified by the community were ranked alongside problems in reproductive health inserted into the list by the researcher. The ranking was undertaken by five displaced and five settled groups. Each problem was ranked according to $(a)$ prevalence, $(b)$ impact on the duration of sickness, $(c)$ impact on mortality, and (d) the availability of treatment. To include illiterate people each disease was 
Examples of scenarios presented in group discussions

Pregnancy outside marriage

A young girl finds that she is pregnant. She is not married. What is she most likely to do? What else could she do? What will happen to her? What else could happen? What would be a good outcome for the girl? What would be a bad outcome for the girl?

\section{Domestic violence}

A married woman is being beaten by her husband more and more often. What is the most likely reason why he is beating her? Who will she talk to about her husband? What will she do to try to stop the situation continuing? What would be a good outcome? What would be a bad outcome for the woman?

represented by a drawing on a card, with the name written below in both English and Arabic. The third technique was the use of scenarios, whereby hypothetical stories of an event are presented to the group or individual who are then asked to state what the outcome would be if that problem occurred in their own community (box). This method is particularly useful in discussing sensitive issues, as the discussion is not based on the experience of any person present. It was used in the group discussions and in-depth interviews.

Secondary data

Secondary data were obtained from health facilities, non-governmental sources, and local administrators.

\section{Analysis}

Interviews with key informants were held in English, whereas all other discussions and interviews were held using translators (three in total) and were usually in Arabic. A minority were held in other local languages. All group discussions were taped in the field and transcribed later, other interviews were written down in full at the time. Analysis of discussions and interviews was undertaken by hand. Lists of topic headings, each with a group of subheadings, were drawn up after the texts had been transcribed and read through several times (examples of these headings are: prevalence of miscarriage; causes of sexually transmitted diseases, etc). The headings were used to develop a card file. The full transcription was photocopied several times. All sections of the text were cut and pasted on to these cards under the relevant headings to amalgamate all comments on the same topic area, when necessary text was pasted under two or more headings. Data from secondary sources, interviews, and observations were then analysed and used to compare results and triangulate the data.

\section{Results}

Within six weeks 20 interviews with key informants, 14 in-depth interviews, and 23 group discussions were undertaken (table 1), either at the two main towns in the area or in nine of the surrounding villages. CAP was present at all except a few group discussions that were run by local leaders or non-governmental workers after a short training period. The group discussions had an average of 11 people, with a minimum of four and a maximum of 23. Groups were made up of people of the same sex and a similar age (with the exception of one mixed sex group). All tribes in the area were represented, and one group discussion was held with soldiers. The key informants included 12 health providers, five local leaders, two representatives from non-governmental organisations (non-health), and one teacher.

All the results cannot be presented in detail here, but a selection have been chosen that illustrate the four main themes identified: $(a)$ there were clear needs in reproductive health; $(b)$ there was a mismatch between the views of service providers and the community; $(c)$ there was variation in the perception of need according to age, sex, and whether the community was settled or displaced; and $(d)$ the lack of supplies coupled with numerous barriers to accessing services.

\section{Clear needs in reproductive health}

The most consistent reproductive health problem identified, often spontaneously, was that of sexually transmitted diseases. Perceived prevalence was very high. Of 11 key informants who ranked diseases in their community in order of prevalence, nine placed sexually transmitted diseases in the top four. Men and women of all ages were concerned about sexually transmitted diseases and their sequelae.

"Sexually transmitted diseases are very common here. Maybe of all of us here, some of us have it."(Group discussion; displaced man.)

The matrix ranking exercise undertaken by some of the groups also showed much concern about sexually transmitted diseases (table 2). The most commonly listed ones were syphilis and gonorrhoea. The symptoms described were often severe, and people described complications such as stillbirth and infertility. Several reasons for the increase in prevalence were given.

"The movement of people and the war has contributed to the spread of these diseases and young men forcing girls to go with them." (Group discussion; settled man.)

Data from the health service confirmed the perceived high prevalence of sexually transmitted diseases. They were the fourth most common reason

Table 1 Demographic data of both groups and individuals interviewed

\begin{tabular}{llll} 
& Interviews with key informants $(\mathbf{n = 2 0}$ & Group discussions $(\mathbf{n}=\mathbf{2 3})$ & In-depth interviews ( $\mathbf{n = 1 4 )}$ \\
\hline Type of community & $\begin{array}{l}\text { Representing settled populations (9); } \\
\text { representing displaced communities (11) }\end{array}$ & $\begin{array}{l}\text { With settled communities (10); with displaced } \\
\text { communities (13) }\end{array}$ & $\begin{array}{l}\text { Displaced communities (7); settled } \\
\text { communities (7) }\end{array}$ \\
\hline Sex & Male respondents (9); female respondents (11) & $\begin{array}{l}\text { Male groups (14); female groups (8); mixed } \\
\text { groups (1) }\end{array}$ & All female \\
\hline Age & Predominantly middle aged (about 25-45 years) & $\begin{array}{l}\text { Groups of young people (5) (about 13-20 years); } \\
\text { groups of middle aged people (14) (about 21-39 } \\
\text { years); groups of older people (4) (40 years and } \\
\text { older) }\end{array}$ \\
\hline
\end{tabular}


Table 2 Ranking of condition according to settled and displaced communities

\begin{tabular}{|c|c|c|c|c|c|c|c|c|}
\hline & \multicolumn{2}{|c|}{ Occurrence } & \multicolumn{2}{|c|}{ Sickness } & \multicolumn{2}{|c|}{ Death } & \multicolumn{2}{|c|}{ Lack of treatment } \\
\hline & Settled & Displaced & Settled & Displaced & Settled & Displaced & Settled & Displaced \\
\hline AIDS & 10th & 10th & 3 rd & 4th & 2nd & $1 \mathrm{st}$ & 1st & 1st \\
\hline Childbirth & 7th & 9th & 9th & 9th & 6th & 7th & 6th & $3 \mathrm{rd}$ \\
\hline Cough & $3 r d$ & $3 r d$ & 5th & 7th & 5th & 9th & 5 th & 8th \\
\hline Diarrhoea & 5th & 4th & $3 \mathrm{rd}$ & 8th & $1 \mathrm{st}$ & $3 r d$ & 6th & 8th \\
\hline Hernia & 4th & 5th & 6th & $3 r d$ & 4th & 2nd & 9th & 2nd \\
\hline Miscarriage & 8th & 7th & 10th & 6th & 7th & 6th & 2nd & 7th \\
\hline Skin diseases & 2nd & 2nd & $1 \mathrm{st}$ & 2nd & 10th & 8th & 10th & 6th \\
\hline Sexually transmitted diseases & 6th & 6th & 2nd & 1st & 8th & $3 r d$ & 4th & 5th \\
\hline
\end{tabular}

A rank of 1st suggests that the disease is a high burden, occurs often, results in many days of sickness or death, or has little treatment available within the community concerned.

for attendance at the main hospital. Altogether 7437 consultations at outpatient departments were for venereal disease (13\% of 33140 total consultations). A survey undertaken in 1995 among attenders of antenatal clinics attenders tested 100 consecutive women for syphilis using the "Macro-Vue" rapid plasma reagin test. ${ }^{25}$ They were also tested for HIV using the ELISA (Detect) and confirmed positive using recombinant HIV-1 and HIV-2 kit (Recombigen). Eleven women $(11 \%)$ tested positive, and $4 \%$ of the women tested positive for HIV.

Miscarriages were the most commonly mentioned problems in reproductive health after sexually transmitted diseases. Among the 14 women interviewed in depth a total of 69 pregnancies were reported. Of these, nine pregnancies were said to have ended in miscarriage, one ended in a stillbirth, and 10 children who were born alive had since died.

"In April and May [1997] the number of miscarriages were very high-about three quarters of pregnant women. (Key informant; community leader.)

The reasons given for the large number of miscarriages included sexually transmitted diseases, other infections, lack of good nutrition, and finally the war itself.

"In 1991 the guns were suffocating, and the sounds of the guns may lead to a miscarriage. The fear of the Antonov [bomber] and the running may also lead to back pain and then miscarriage." (Key informant; community leader.)

Perceptions about the incidence of sexual violence were conflicting. Some key informants thought that the incidence was falling, but others disagreed. Few women were prepared to discuss this issue; those that did stated that the perpetrators of violence were deserters from the army. One group of internally displaced people had moved their homes away from the road to avoid contact with these people,

"The other problem women face is deserters. They can do anything and force you to sleep with them. Sometimes three or four of them one after the other." (Key informant; outreach worker.)

Although the judicial system was apparently working, women would not always admit to violent incidents.

"The other thing is this silent rape. Women go to the bush, and they get raped. They don't say anything." (Key informant; health service provider.)

During discussion of a scenario about rape those at risk were identified and so were possible outcomes.
"Younger girls and women collecting water and firewood away from the house are at risk [of rape] ... She will be happy if the husband agrees to stay with her. If he refuses, it will make her unhappy and ashamed to stay in that community." (Group discussion; displaced men.)

\section{Mismatch between the views of service providers} and those of the community

Some providers of health services stated that abortions were not taking place, but discussions with local people revealed that abortion was an issue.

"Some people don't want to be pregnant, they take herbs and chloroquine injections by breaking the glass and drinking it. They also take Omo [a washing powder] ... people die because of this." (Key informant; community leader.)

These methods of abortion were described in response to a scenario.

"Sometimes girls use batteries-99\% of the girls who do this will die. They pound the batteries, and then they put it in water and drink." (Group discussion; young settled girls.)

Similarly, some service providers thought that domestic violence was not occurring.

"Violence against women is not occurring in southern Sudan as women are treasured." (Key informant; health service provider.)

Group discussions with men and women, as well as in-depth interviews, showed that this was not always true.

"No stranger has been violent to me, but at home this violence is normal." (In-depth interview; internally displaced woman.)

Responses to scenarios provided information on the context of the violence.

"The reasons for beating are mismanagement of funds, misconduct, if the woman refuses to have sex with her husband, improper way of receiving visitors, infidelity, abuse of her husband, rumour mongering, and theft .... Some husbands are always drunk and don't provide for their wife or children ... when the wife asks him he just starts beating the wife." (Group discussion; displaced men)

Perceptions of the prevalence of problems occurring in labour also varied. Some service providers thought that "not many women die in childbirth," or said "I don't think the problems are too bad." There was a recognition, however, that it was difficult for them to obtain accurate information. 
"I don't think too many women are dying, but if a women dies in the village she will be buried, and there is no way of knowing." (Key informant interview; health service provider.)

In group discussions maternal mortality and morbidity were perceived to be high.

"Yes, yes, yes, we know of many women who die in childbirth. We know of about nine in the last year." (Group discussion; settled women.)

Secondary data collated from primary care centres suggested maternal mortality ratios as high as 845 per 100000 live births.

Differences in perceived need according to age, sex, and degree of displacement

Different age and sex groups within the communities held different views. Older men in the settled community were least likely to think childbirth and miscarriage were common problems, ranking them last. Young women, however, ranked them third and sixth. Men thought that the extent of maternal mortality and morbidity was not great among their community.

"Some women die but it is not that common." (Group discussion; displaced men.)

Women, however, thought that many women were dying and others suffering complications after birth.

"Many women die in childbirth. Seven to eight last year. Also there are cases of the child dying inside the mother. This problem was there before but has now increased." (Group discussion; displaced women.)

Differences in views were also identified between whether people were settled or displaced. The ranking exercise showed that although the perceived occurrence of disease was similar in both communities, the availability of treatment and the impact of different diseases in terms of duration of sickness and death varied considerably (table 2). When asked about general threats, people in the settled community were most likely to mention health, complaining about "continuous death" and "lack of medicines." People in the displaced community were often more concerned about food and materials.

"Since we have returned from Congo we have had no proper food, nothing to cover the children, no cooking materials, no proper shelter, nothing to dress in so we are ashamed to meet people, and no salt or washing powder." (Group discussion; displaced women.)

When people were specifically asked, however, to list common diseases aspects of reproductive health were spontaneously included by both settled and internally displaced populations. Those mentioned were sexually transmitted diseases, miscarriages, problems in childbirth, and infertility.

\section{Paucity of supplies and numerous barriers to accessing services}

Communities complained about a lack of medical supplies.

"Sometimes people go to the hospital for treatment but the medicine will not be there until you die." (Group discussion; settled men, and a health provider agreed.)
"Every trained midwife gets a delivery kit and this needs replacing but this does not happen." (Key informant; health service provider.)

Reported barriers to accessing services were: difficulties in obtaining transport; a reluctance to admit to sexually transmitted infections; traditional beliefs; and conflicting demands on women. The following information was given in response to a scenario.

"In most cases women are shy [to go for treatment for sexually transmitted diseases] and don't go to the hospital unless the man also gets the disease. She will just stay with it." (Group discussion; displaced men.)

\section{Discussion}

Pottier described the lack of knowledge that providers have about refugee perspectives as having two main costs-namely, that a professional service is not carried out to the best of one's ability and that there is a reduction in refugee confidence in humanitarian agencies and their workers. ${ }^{26}$ Currently agencies are struggling to decide what reproductive health services should be provided in the context of conflicts, but little attention has been paid to the views of the communities themselves. The link between including men and women in assessing the needs of communities and a resulting increase in the quality of services has previously been noted. ${ }^{27}$

\section{Advantages of community participation}

In this assessment of need several important potential benefits resulted from including the community, which have implications for humanitarian aid in general.

Firstly, the methods resulted in insights about the perceptions, values, and priorities of members of the community. The limitations of many assessments, based as they are on consulting with leaders (often older men) and service providers were overcome.

Secondly, group discussions were held with groups of different age and sex, allowing the exploration of the relative importance paid to various aspects of reproductive health by these different groups. The additional information from the community highlighted problems that affected particular groups and also uncovered new concerns, such as abortion.

Thirdly, information was obtained about traditional beliefs and other attitudes that decreased use of health services.

Fourthly, participation of the community in the data collection increased awareness of the issues among members of the community and some spontaneous ideas for solutions. For example, debates started about how to provide information about sexually transmitted diseases, and church leaders suggested that this information could be provided at church services.

The study benefited from the cooperation of key local figures, including representatives of local women's associations and a respected Sudanese Oxfam worker, who translated at most discussions and interviews. Qualitative information was supplemented where possible by quantitative data. Such supplementation to findings of rapid appraisal can and did strengthen the results. 
Funding: The work was undertaken while CAP was employed as a senior registrar in public health on the North Thames training scheme. It was funded by the Central Research Fund of London University and Ines Smyth in her capacity as a member of the Global Reproductive Health Policies Group. Oxfam UK provided logistical assistance. Competing interests: None declared.

1 Macrae J, Zwi A, eds. War and hunger-rethinking international responses to complex emergencies. London/Atlantic Highlands, New Jersey: Zed Books in association with Save the Children Fund, 1994.

2 Harrell-Bond BE. Imposing aid: emergency assistance to refugees. Oxford: Oxford University Press, 1986.

3 Hancock G. Lords of poverty. London: Mandarin Paperbacks, 1991.

4 Borton J. Joint evaluation of emergency assistance to Rwanda. The international response to conflict and genocide: Lessons from the Rwanda experience. Section 3. Humanitarian aid and effects. Odense:Steering Committee of the Joint Evaluation of Emergency Assistance to Rwanda, 1996.

5 Basikila P, Male S, Lindgren J, Roberts L, Robinson D, Stettler N, et al. Public health impact of Rwandan refugee crisis: what happened in Goma, Zaire, in July, 1994? Lancet 1995;345(8946):339-44.

6 Hendrie B. Knowledge and power: a critique of an international relief operation. Disasters 1997;21(1):57-76

7 International Federation of the Red Cross and Red Crescent Societies, eds. World disasters report. Geneva, 1994.

8 United Nations. Population and development: programme of action adopted at the international conference on population and development, Cairo, 5-13 September 1994. New York: Department for Economic and Social Analysis, United Nations, 1995. (ST/ESA/SER.A/149.)

Limitations of study

The study had several limitations. Firstly, information was being sought specifically on reproductive health, and therefore a bias may have existed to find positive data about these issues. Secondly, the study could not be described as truly participatory as local people did not take part in planning the study, analysing, or presenting the results. A design effect may have occurred as the women selected for in-depth interviews were living in close proximity to each other. Only one researcher participated in analysing the data because of resource limitations, possibly biasing the results. The time scale of this type of study is rarely as rapid as the name suggests. The full results in this case were available about three months after the work was started. A less rigorous but nevertheless valid overview, however, was quickly obtained during the process of the systematic gathering of information.

\section{Conclusion}

Preliminary results were fed back to the communities during the study. Changes in local implementation as a result of the study were limited as a result of a diversion of aid into neighbouring parts of Sudan because of famine. The study did, however, affect the planning of more recent programmes, which are being extended to provide an element of reproductive health care. The type and depth of information obtained through this study suggest that rapid appraisal could be useful as a first step in including communities in assessing needs and planning the provision of services. Further research is needed into barriers that agencies face, in order to ensure that consultation with communities can become a routine part of needs assessment and the planning of service provision in relief contexts.

Contributors: CAP designed the study, obtained funding, collected the data in the field, analysed the data, and wrote the paper. Anthony Zwi contributed advice at the design stage along with other colleagues at the London School of Hygiene and Tropical Medicine (particularly Jessica Ogden and Louisiana Lush) and members of Oxfam (UK). AZ also made detailed comments on an earlier draft of the paper. Oliver Rooke edited the final version and successive drafts. The local Oxfam team (who cannot be named for security reasons) provided logistical support, translation, and invaluable advice. The community leaders in the area were all supportive and CAP thanks all those who gave up their time to talk to her.
9 Palmer CA, Lush L, Zwi AB. The emerging international policy agenda for reproductive health in conflict settings. Soc Sci Med 1999;49:16891703. (In press.)

10 Palmer C. Reproductive health for displaced populations. London: Overseas Development Institute, 1998. (Relief and Rehabilitation Network Paper 24.)

11 Glass RI, Cates W, Nieburg P, Davis C, Russbach R, Nothdurft H, et al. Rapid assessment of health status and preventative medicine needs of newly arrived Kampuchean refugees. Sa Kaeo, Thailand. Lancet 1980;i:868-72

12 Shears P, Berry A, Murphy R, Aziz Nabil M. Epidemiological assessment of the health and nutrition of Ethiopian refugees in emergency camps in Sudan. BMJ 1985;295: 314-8.

13 Guha-Sapir D. Rapid assessment of health needs in mass emergencies: review of current concepts and methods. World Health Stat $Q$ 1991;44:171-80.

14 Chambers R. Rapid rural appraisal: rationale and repertoire. Public

15 Scrimshaw SCM, Hurtado E. Rapid assessment procedures for nutrition and Tokyo: United Nations University, 1987.

16 Melville B. Rapid rural appraisal: its role in health planning in developing countries. Trop Doct 1993;235;5-8

17 Murray SA. Experiences in raid appraisal in primary care: involving the public in assessing health needs, orienting staff and educating medical students. BMJ 1999;318:440-4.

18 Annett H, Rifkin S. Guidelines for rapid appraisal to assess community health needs. Geneva: World Health Organisation, 1990

19 Kulig JC. Conception and birth control use: Cambodian refugee womens beliefs and practices. J Commun Health Nurs 1988;5:235-46.

20 Kulig JC. Role, status and family planning use among Cambodian refugee women. Ann Arbor: University Microfilms International, 1991:222.

21 Berglund S Liljestrand J, Marin F, Salgado N, Zelaya E. The background of adolescent pregnancies in Nicaragua: a qualitative approach. Soc Sci Med 1997;44:1-12.

22 Pelto PJ. Data gathering for reproductive health research. London: London School of Hygiene and Tropical Medicine, 1998.

23 Weller SC, Romney AK. Systematic data collection. Qualitative research methods. London: Sage, 1988.

24 Welbourn A, ed. Rapid rural appraisal notes: special issue on applications for health. London: International Institute for Environment and Development, 1992.

25 Onwere S. Assessment of STDs in Maridi County. Nairobi: Action Afrika Hilfe, 1995

26 Pottier J. Why aid agencies need better understanding of the communities they assist: the experience of food aid in Rwandan refugee camps. Disasters 1996; 20:324-37.

27 Palmer CA, Zwi AB. Women, health and humanitarian aid in conflict. Disasters 1998:22:236-49.

\section{Endpiece \\ Next best thing}

When W H Auden once found him playing that game [patience] and asked him why he seemed to relish it, he reflected gravely and then replied, "Well, I suppose it's the nearest thing to being dead."

Peter Ackroyd, T S Eliot, Penguin, 1993 Admin Dev 1981:1:95-106 primary care. Anthropological approaches to improving programme effectiveness.

(Accepted 25 August 1999) 